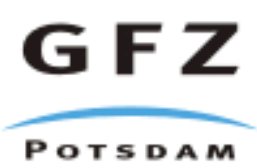

Originally published as:

Milke, R., Abart, R., Kunze, K., Koch-Müller, M., Schmid, D., Ulmer, P. (2009): Matrix rheology effects on reaction rim growth I: evidence from orthopyroxene rim growth experiments. - Journal of Metamorphic Geology, 27, 1, 71-82

DOI: 10.1111/j.1525-1314.2008.00804.X 


\section{Matrix rheology effects on reaction rim growth I: evidence from orthopyroxene rim growth experiments}

Milke, R. ${ }^{1}$, Abart, R. ${ }^{1}$, Kunze, K. ${ }^{2}$, Koch-Müller, M. ${ }^{3}$, Schmid, D. ${ }^{4}$, Ulmer, P. ${ }^{5}$

Corresponding author:

Ralf Milke

milke@zedat.fu-berlin.de

${ }^{1}$ Institut für Geologische Wissenschaften

Freie Universität Berlin

Malteserstrasse 74-100

12249 Berlin, Germany

${ }^{2}$ ETH Zürich, Electron Microscopy Center Zurich, Switzerland

${ }^{3}$ GeoForschungsZentrum Potsdam, Dept. 4.1, Experimental Geochemistry and Mineral Physics

${ }^{4}$ Physics of Geological Processes (PGP), University of Oslo, Norway

${ }^{5}$ ETH Zürich, Institut für Mineralogie und Petrographie, Switzerland 


\section{ABSTRACT}

The rim-forming reaction quartz + olivine $=$ orthopyroxene is used to investigate the effect of matrix rheology on rim growth rates. Orthopyroxene rim growth around olivine grains in quartz matrix is compared to rim growth around quartz grains in olivine matrix. At constant $P$ and $T$, within one single capsule, orthopyroxene rims grow faster around quartz clasts in olivine matrix than around olivine clasts in quartz matrix. Fourier transform infra-red (FTIR) spectra indicate that the entire samples are water saturated due to water adsorption on the reactant grain surfaces. The increased orthopyroxene growth rates in olivine matrix as opposed to quartz matrix are interpreted in terms of matrix rheology, where in the two different matrix-inclusion arrangements the olivine matrix behaves "softer" and the quartz matrix "more rigid". The strain energy associated with accommodation of the negative reaction volume is higher for the quartz than the olivine matrix and reduces the free energy that drives orthopyroxene rim growth. Growth textures in both kinds of orthopyroxene rims indicate that the diffusivity of $\mathrm{MgO}$ slightly exceeds the diffusivity of $\mathrm{SiO}_{2}$. The relative mobility of $\mathrm{MgO}$ and $\mathrm{SiO}_{2}$ at given $\mathrm{P}, \mathrm{T}, \mathrm{fH}_{2} \mathrm{O}$ seems to be controlled by energy minimization during orthopyroxene growth at the compressive $\mathrm{Ol} / \mathrm{Opx}$ interface.

Our experiments provide evidence for two previously overlooked effects relevant to rim growth reactions in metamorphic rocks:

- diffusivity along chemical potential gradients to reaction sites is a function of rheology;

- the relative diffusivity of components during reaction rim or corona growth is a function of local volume changes at the rim's interfaces. 


\section{INTRODUCTION}

The formation of a reaction rim between two mutually incompatible mineral phases requires mass transfer across the growing rim. The growth of a monomineralic reaction rim can be considered a simplified case of the formation of polymineralic and often zoned reaction bands or coronas that are common phenomena in metamorphic and magmatic rocks (e.g. Griffin, 1971; Fisher, 1978; Foster, 1981; Sack, 1982; Mongkoltip \& Ashworth, 1983; Nishiyama, 1983; Griffin et al., 1985; Joesten, 1986; Joesten \& Fisher, 1988; Grant, 1988; Ashworth \& Birdi, 1990; Johnson \& Carlson, 1990; Carlson \& Johnson, 1991; Ashworth et al., 1992a,b; Carlson et al., 1995; Ashworth \& Sheplev, 1997; Attoh, 1998; Ashworth et al., 1998; Markl et al., 1998; Ruzička, 1998; Foster, 1999; Abart et al., 2001; Carlson, 2002). In several experimental studies it was found that under isothermal-isobaric conditions reaction rim thickness increases linearly with the square root of time. Such behavior is expected for diffusion-controlled kinetics (e.g. Fisler \& Mackwell, 1994; Fisler et al., 1997; Yund, 1997; Liu et al., 1997; Watson \& Price, 2001; Milke \& Heinrich, 2002) and motivated a series of studies that employed rim growth experiments to determine component mobilities.

In general, mineral reactions are accompanied by volume change. As such, for reactions within solid rocks, any volume change induces stress and leads to deformation around the reaction site. If the reaction volume is positive $(\Delta \mathrm{V}>0)$, mass must be transported in the direction away from the reaction site to create space for the reaction products. In the case where $\Delta \mathrm{V}<0$ free space must be closed by material transport towards the reaction site. If an interconnected pore fluid is present that serves as solvent for the mobile components, volume changes may be readily accommodated by dissolution-precipitation and transport through the pore fluid (Putnis \& Mezger, 2004). If these processes are fast compared to the mineral reaction that produces the volume misfit, the reaction can occur stress-free irrespective of volume changes of the solid phases (Merino \& Dewers, 1998). Such behavior is well known from diagenetic and metamorphic settings and leads to the formation of pseudomorphs (Putnis, 2002). If the mineral reaction that creates the volume misfit is fast, the rate of volume change may exceed the rate at which the rock matrix may accommodate strain by fluid bound mass transfer, even in water-rich environments. An example is the reaction periclase + water $=$ brucite that induces strong volume increase, such that the product crystals show features of reaction-induced stress and deformation (Carmichael, 1987).

Where a rock lacks an interconnected pore fluid, material transport occurs along pathways within the mineral grains or along the grain- and phase boundaries. Transport under fluid absent conditions is substantially slower than in fluid saturated systems (Joesten, 1991). In such settings two processes act in mutual competition: first, rim growth producing volume change and, second, matrix deformation under stress relaxation. In general, the stress induced by the volume change associated with rim growth will act against the reaction and slow down or eventually stop the reaction. The extent to which the reaction induced stress changes the reaction rate depends on the relative ease of mass transfer across the reaction rim and deformation of the rock matrix. If mass transfer across the reaction rim is fast and the effective viscosity of the matrix is high, then deformation of the rock matrix may be rate limiting and the rim growth rate is controlled by the rheology of the rock. If the matrix has a low effective viscosity and mass transfer across the reaction rim is sluggish, the latter process may be rate limiting and rim growth is essentially controlled by component diffusion across the reaction rim.

Here we show our results on the role of matrix rheology on reaction rim growth. We did experiments on the well-studied reaction olivine + quartz $=$ orthopyroxene (Fisler et al., 1997; Yund, 1997; Milke et al., 2001; Abart et al., 2004; Milke et al., 2007). $\Delta \mathrm{V}$ of this reaction is negative $(\Delta \mathrm{V}=-6 \%)$. In piston cylinder experiments under high confining pressure (1 GPa) 
we compared the rim growth rates for the cases where quartz grains were immersed in an olivine matrix and where olivine grains were immersed in a quartz matrix. To ensure identical run conditions for both matrix-inclusion arrangements both kinds of reaction rims were synthesized side by side within a single capsule in one experimental run. With systematic measurement of orthopyroxene rim thickness for both setups, we investigate whether the matrix-inclusion arrangement has an influence on rim growth rate.

\section{EXPERIMENTAL AND ANALYTICAL PROCEDURES}

Experiments were done using a finely ground and a coarser fraction of olivine and quartz, respectively. In one half of the capsules olivine grains were interspersed in a fine grained quartz matrix, and in the other half vice versa. Quartz was synthetic quartz (TOYO, Japan) sieved to 11-20 $\mu \mathrm{m}$ and clear Brazilian quartz sieved to 125-200 $\mu \mathrm{m}$. Olivine was natural olivine from San Carlos, Arizona, USA (about $90 \mathrm{~mol} \%$ forsterite), either unsieved fine powder with most grains between 10-30 $\mu \mathrm{m}$ diameter (some larger) or a 125-200 $\mu \mathrm{m}$ sieve fraction. Starting mixtures were prepared with $90 \mathrm{wt} \%$ of one reactant in fine grain size interspersed with $10 \%$ coarser clasts of the other reactant. The reactant mixtures were charged in $2 \mathrm{~mm}$ wide and about $10 \mathrm{~mm}$ long platinum or gold palladium (Au75Pd25) capsules. The mineral powder was compacted with a hand piston such that the capsules remained in a cylindrical shape through the high pressure runs. Where one capsule contained two starting mixtures, their interface was sharp and stayed undeformed during the experiment. There was no drying off of adsorbed water from the reactant grain surfaces before weld sealing the capsules. The experiments were performed in a non-endloaded piston-cylinder apparatus using corundum-pyrex-boron nitride pressure assemblies with the capsules being embedded in BN. Temperature was measured using Pt6Rh-Pt30Rh (B-type) thermocouples with the tip located close to the central part of the capsules.

After the experiments the capsules were cut lengthwise in two halves and polished and thin sections were produced for optical and scanning electron microscopy (SEM) and electron back-scatter diffraction (EBSD) investigations. Rim thickness measurements in QFFQ01 were made from back-scattered electron images taken with a Philips XL 30 ESEM at $20 \mathrm{kV}$ acceleration voltage. To minimize cutting effects each reaction rim was measured 3 times on serial sections, where $c .20 \mu \mathrm{m}$ of material were removed from the sample surface by grinding and polishing in between two successive measurements. The lowest value found on each rim during these 3 cycles was considered to best represent the real thickness and was used in this study. Rim thickness measurements in QFFQ02 were made by optical microscopy from a thin section. While BSE images only show the sample surface, light optical measurements allow the entire slice of the rim in the thin section to be taken into account and thus help to eliminate cutting effects. On the other hand, due to the minuteness of the rims the measurements are less accurate. Additional BSE images were made using a JEOL Hyperprobe JXA $8500 \mathrm{~F}$ field emission microprobe at $6 \mathrm{kV}$ acceleration voltage. For EBSD analysis the sample surface was ultra-polished using colloidal silica suspension in order to remove any preparation induced surface damage. EBSD images were taken from steeply tilted sample surfaces $\left(70^{\circ}\right)$ under a long working distance $(35 \mathrm{~mm})$ with a step size of $0.5 \mu \mathrm{m}$.

Fourier transform infra-red microspectrometry (FTIR) was done using a Bruker IFS 66v spectrometer with attached IR-microscope (Bruker Hyperion 1000). The maximum spectral resolution is $0.25 \mathrm{~cm}^{-1}$ and the spatial resolution is about $20 \mu \mathrm{m}$. IR spectra of olivine starting material were taken in 3 vertical directions from polished olivine cubes. For FTIR measurements of adsorbed water the un-reacted powder was pressed to a disk of defined thickness. A gasket with a sample chamber $200 \times 150 \mu \mathrm{m}$ in size was placed on the lower anvil of a diamond anvil cell and the mineral powder was pressed with the upper anvil by 
hand to a solid plate. The gasket with the mineral powder could be directly placed under the IR-microscope without any support. For desorption tests and high precision measurements a heating/cooling stage (Linkham THM600) was used under the IR-microscope. For FTIR investigation of olivine and quartz after reaction a $100 \mu \mathrm{m}$ thick plate with double-sided polish was prepared (W. Tschudin, Geoprep/Basel, Switzerland).

\section{RESULTS}

The results of the three experimental runs are given in Table 1. All three experiments lasted for 80 hours at $1000{ }^{\circ} \mathrm{C}$ and $1 \mathrm{GPa}$. In the first experiment two capsules were placed side by side inside the BN center piece containing the mixtures QF01 (quartz clasts in olivine matrix) and FQ01 (olivine clasts in quartz matrix). In the second and third experiments both mixtures were contained together in one single capsule with each mixture comprising one half of the charge. By this modification it was made sure that both mixtures reacted under completely identical run conditions.

\section{Experiment with two capsules}

The average orthopyroxene rim thickness in QF01 (quartz clasts in olivine matrix) was $29.8 \pm$ $8.8 \mu \mathrm{m}$, but only $3.2 \pm 0.8 \mu \mathrm{m}$ in FQ01 (olivine clasts in quartz matrix). Orthopyroxene rims around olivine in quartz had the same appearance as in earlier experiments (Milke et al., 2001) with a smooth Ol/Opx interface and rough Opx/Qtz interface made up of many facetted crystal terminations. Interfaces of orthopyroxene rims around quartz grains in olivine were very similar, now with the faceted crystal terminations pointing inward the concentric rim structures (Fig. 1). In accordance with earlier observations (Abart et al., 2004) the orthopyroxene on the quartz side of the rims has a higher electron back scatter capacity than on the olivine side, pointing to an enrichment of iron in orthopyroxene formed at the Opx/Qtz interface. Such zoning is present in both kinds of orthopyroxene rims. In both reaction products isolated pores on triple junctions of the respective matrix minerals are present indicating the presence of limited fractions of an aqueous fluid under run conditions. In sample QF01 additional pores immediately on the rim interfaces were observed, in part filled with needle-like orthopyroxene crystals (Fig. 1), suggesting a higher water content in this capsule than in FQ01 for whatever reason.

\section{Experiments with two mixtures in one capsule}

\section{Rim thickness}

To rule out the possibility of different water contents that may have been produced by placing the two matrix-inclusion arrangements in separate capsules, the design was modified to one single welded capsule with each reactant mixture making up one half of the filling. Two experiments, QFFQ01 and QFFQ02, were carried out. Measured rim thickness is given in Table 1 and depicted in Fig. 2. In both experiments orthopyroxene rims around the quartz clasts in the olivine matrix are thicker than around the olivine clasts in the quartz matrix. The rim thickness is relatively uniform within the two domains with different matrix-inclusion arrangements. A distinct step in rim thickness is observed at the interface of the two starting mixtures (Fig. 2). In QFFQ01 rim thickness squared $\left(\mathrm{d}^{2}\right)$ in the quartz in olivine arrangement is about 3 times larger than for the olivine in quartz arrangement. In QFFQ02 similar systematics were observed, but $\mathrm{d}^{2}$ for the quartz in olivine arrangement was only about twice the $\mathrm{d}^{2}$ that is observed in the olivine in quartz arrangement. 
During the determination of rim thickness care was taken to include rims from all over the capsule. In QFFQ01 the choice of grains had to be made during the first round of measurements and rims were selected that appeared to have been cut approximately in the center of the core-rim structures and with core-rim interfaces normal to the sample surface. Due to insufficient homogenization of the starting mixture there were only three rimmed quartz clasts present near the ending of the capsule on the olivine matrix side. Two of them almost disappeared during the subsequent polishment steps and were obviously cut in an unfortunate position that exaggerated the rim thickness. One olivine grain immediately at the interface of the quartz and olivine matrices showed an increased rim thickness typical of the rims around adjacent quartz grains. Apparently, this grain was in direct mechanical contact to the olivine matrix. Except for these special situations two distinct plateau values emerged for the thickness of orthopyroxene rims around olivine in quartz and quartz in olivine. Remarkably, all orthopyroxene rims around olivine clasts in the quartz matrix were thinner than all rims around quartz clasts in the olivine matrix.

\section{Growth textures}

The orthopyroxene rims are always separated into two microstructurally different domains, separated by a textural discontinuity that parallels the interfaces and is taken to represent the original Qtz/Ol contact. Thus, to each orthopyroxene-forming partial reaction at the interfaces pertains a distinct growth texture. The textural discontinuity seperating these zones coincides with the change in electron back-scatter contrast mentioned above. In orthopyroxene rims around olivine the zone next to the Opx/Ol interface is always wider, and the change in texture is located at about two thirds of the total rim thickness. The Opx/Ol interface is smooth in both matrix-inclusion arrangements, and the Opx/Qtz interface rough and irregular due to elongate orthopyroxene crystals pointing into the quartz grains. The orthopyroxene formed at the $\mathrm{Opx} / \mathrm{Ol}$ interface has a weak palisade-like shape preferred orientation. A crystal preferred orientation could not be identified in the palisades. The orthopyroxene formed at the Opx/Qtz interface is micro-granoblastic with a few grains elongated parallel to the interface, and without any lattice preferred orientation.

In orthopyroxene rims around quartz clasts the textural boundary is rather located in the middle of the rims. The separation between the two parts is visible in light optical and EBSD images despite the fact that both have a palisade-like shape preferred orientation elongated in the direction normal to the interface. The orthopyroxene palisades grown at the Opx/Qtz interface have a very distinct crystal preferred orientation. They show straight extinction with respect to their long axis, positive elongation, and with use of a lambda plate show identical addition and subtraction interference colors as the quartz grains in the matrix. All these observations are consistent with the c-axes being normal to the Opx/Qtz interface. In contrast, the orthopyroxene palisades formed at the Opx/Ol interface do not show any lattice preferred orientation; neither do they show any correlation with the crystallographic orientation of the adjacent olivine grains nor with their neighboring orthopyroxene crystals.

\section{FTIR measurements of olivine and quartz}

Results from the FTIR measurements are summarized in Table 2. Olivine showed the typical dominant absorbance in all polarisations between 3650 and $3100 \mathrm{~cm}^{-1}$ (e.g. Bell et al., 2003). The intrinsic $\mathrm{OH}$ content in olivine was determined from three grains according to the calibration of Bell et al. (2003) and averaged at 1.2-1.6 wt-ppm (Fig. 3). This result is consistent with 0.2-0.7 wt-ppm as determined by Miller et al. (1987) who used the calibration 
after Paterson (1982) that compared to Bell (2003) underrates $\mathrm{OH}$ by a factor of about 3 . OH in reactant quartz was not measured.

For the determination of the amount of adsorbed water fine reactant powder as used as matrix phase in the rim growth experiments was dried at $110{ }^{\circ} \mathrm{C}$, then pressed to a pellet in a diamond anvil cell, and the total integrated absorbance in the 3750 to $3100 \mathrm{~cm}^{-1}$ region was repeatedly measured in ambient air. $\mathrm{OH}$ on both olivine and quartz continuously increased with time whereby adsorption on olivine generally was ahead of quartz and after 2 hours values of $0.24 \mathrm{wt} \%$ on olivine and $0.21 \mathrm{wt} \%$ on quartz (calibration after Libowitzky, 1997) were reached. The measurements were done in a cool, air conditioned laboratory and can only be regarded as an example since adsorption certainly varies largely depending on room temperature and air humidity. Water concentrations in QFFQ01 and QFFQ02 are thus inferred to be in the $2000 \mathrm{ppm}$ range. With increasing temperature on a heating stage the water on both olivine and quartz powders desorbed continuously and was not detectable any more at $400{ }^{\circ} \mathrm{C}$ (Fig. 3).

Intracrystalline $\mathrm{OH}$ in olivine and quartz after reaction was measured in the experiment QFFQ02. Spectra from quartz grains come from the clasts embedded in olivine in one half of the capsule. Olivine was measured in the clasts in quartz matrix and in the scattered large grains within the olivine matrix (Fig. 4). Since the crystallographic orientation of the grains was not known, numerous measurements were taken to obtain maximum values for $\mathrm{OH}$ content on a statistical basis (Fig. 3). Compared to the San Carlos olivine starting material there is increased absorbance at wave numbers between 3400 and $3200 \mathrm{~cm}^{-1}$, as known from experimentally hydrated forsterite (Bai \& Kohlstedt, 1993). OH concentrations in olivine clasts within the quartz matrix and in large matrix grains are practically identical with values of 79 and 76 wt-ppm water, respectively. The water content in quartz is 28 wt-ppm.

\section{DISCUSSION}

\section{Influence of matrix rheology on rim growth rates}

In order to evaluate the effect of matrix rheology on rim growth rates all other factors, which potentially could influence reaction kinetics have to be eliminated. Small amounts of water adsorbed on grain surfaces can substantially enhance rim growth (Milke et al., 2007), a feature not readily controlled using conventional experimental techniques. The two experiments QF1 and FQ1 point to the problems emerging from the use of separate capsules, even within the same experimental run. According to the FTIR measurements a higher total water content can be expected in the samples with olivine matrix, but the difference in water adsorption does not seem large enough to explain the observed difference in rim growth rates. The 10-fold increase in rim thickness around quartz grains in olivine matrix was only observed when the two matrix-inclusion arrangements were loaded in separate capsules. The difference in rim width was substantially lower in the experiments with both mixtures in a single capsule. It may be hypothesised that this discrepancy is due to higher total water content in the capsule with the quartz in olivine arrangement, but this supposition was not tested systematically. To ensure identical run conditions, in particular a homogeneous distribution of water, the two matrix-inclusion arrangements were loaded side by side into a single capsule. In the desorption experiments where the studied powder was pressed to a thin plate at an estimated pressure of 500 to $1000 \mathrm{MPa}$, water disappeared from the FTIR spectra at $400{ }^{\circ} \mathrm{C}$. It is thus inferred that adsorbed water homogenized within the capsules during the heating-up procedure that was accomplished at a pressure somewhat below the target pressure of $1000 \mathrm{MPa}$. The constant water contents in olivine along the entire length of the QFFQ02 capsule indicate homogeneous distribution and overall water saturation. The observed $\mathrm{OH}-$ 
concentrations in olivine (Table 2) are well in accordance with the solubility data of Bai \& Kohlstedt (1993) and Matveev et al. (2001) taking into account that these authors used the calibration after Paterson (1982) and that our experiments were not controlled with respect to oxygen fugacity. Considering these observations, spatial variations in water content can be ruled out as a possible explanation for the different orthopyroxene rim growth rates in the two starting mixtures. This conclusion is further backed up by the plateau values for rim thickness in the two compartments (Fig. 2), because spatial variations in water content should rather lead to a smooth distribution in rim sizes than two distinct plateaus. This last argument also indicates that the observed variations in rim thickness were not due to temperature gradients that may be present along the samples, since a continuous variation of the temperature would as well be in conflict with the sharp step in rim thickness at the interface between the two domains. Taking all factors into consideration the remaining candidate to explain the observed difference in rim growth rates at the interface of the two matrices is the influence of matrix rheology. The local stress regime at rim growth sites is a function of confining pressure, volume change associate with rim growth, and the rheology of the matrix material.

\section{Growth fabrics}

The internal microfabrics and textures of the reaction rims are potential indicators for local stress states. In Fig. 5 a synopsis is provided of the observations from optical microscopy, and foreward and back-scattered electron microscopy. In rims from polymorphic phase transformations that produce a volume increase within confined space, for example the coesite to quartz conversion in inclusions in garnet from UHP rocks (Chopin et al., 1991; Mosenfelder \& Bohlen, 1997; Guiraud \& Powell, 2006), crystal growth occurs under compressive stress. Palisade growth is a common feature in such environments (Mosenfelder et al., 2000), i.e. elongated crystals with their long axis oriented vertically to the polymorphic transformation front, in the absence of a lattice preferred orientation. An analoguous microstructure was identified in wollastonite reaction rims around quartz grains where growth at the wollastonite-quartz interface occured in restricted space and therefore induced compressive stress (Milke \& Wirth, 2003). In the present experimental samples palisade textures without lattice preferred orientation were observed at the Opx/Ol interfaces of the rims in both matrix-inclusion arrangements.

Sharp contrasts in fabric allow the position of the initial Ol/Qtz contact to be identified and to equate the relative widths of orthopyroxene crystallised at either or the other interface (Fig. 5). Care must be taken not to equal the relative widths of the zones with their volume relations, because geometrical effects induced by sphericity always lead to exaggerated widths of the inner compared to the outer zone. In rims around olivine clasts about $2 / 3$ of the rim width is made up of indistinct palisades grown at the Opx/Ol interface. This proportion indicates that orthopyroxene replaces olivine at close to constant volume (relation 62:38), in accordance with stress minimization of a reaction in confined space (Abart et al., 2004). This implies that the flux of the $\mathrm{MgO}$ component across the growing rim was larger than the flux of the $\mathrm{SiO}_{2}$ component by a factor of about 1.5 . In rims around quartz clasts only about half the volume of the orthopyroxene rims seem to have formed at the Opx/Ol interface. This proportion could indicate that rim growth evolved primarily by diffusion of the $\mathrm{MgO}$ component from the O1/Opx to the Qtz/Opx interface with only minor counter diffusion of the $\mathrm{SiO}_{2}$ component (Fig. 6). However, considering sphericity, also this situation is near to constant volume replacement at the $\mathrm{Opx} / \mathrm{Ol}$ interface. Indeed, where fluids preserved open pores in the 2-capsule experiment, porosity was found at the Opx/Qtz interface in rims around quartz clasts. In the single-capsule experiments less water was present and no obvious porosity was present at this interface, but the general appearance of the rims was very similar. From these observations we conclude, that the original Ol/Qtz interface was shifted with 
respect to an external reference frame, such that the compressive stress at the Opx/Ol interface was minimized and only transient porosity was present at the Opx/Qtz boundary.

At the Opx/Qtz interfaces of the two arrangements orthopyroxene crystallises in different fabrics. In rims around olivine clasts orthopyroxene is granoblastic with a few large orthopyroxene crystals elongated in the direction parallel to the interface, and no lattice preferred orientation (cf. Abart et al., 2004). In rims around quartz clasts orthopyroxene crystallizes at the Opx/Qtz interface in palisades with [001] oriented normal to the interface. Both growth fabrics are typical for crystal growth in open voids, where the crystallization was non-competitive around olivine clasts, and competitive around quartz clasts. Although there are no persistent voids at the Qtz/Opx interface of the quenched samples, the growth structures speak for the presence of transient porosity, if only on molecular scale, during rim growth.

In contrast, the shape preferred orientation without lattice preferred orientation at $\mathrm{Opx} / \mathrm{Ol}$ in rims around quartz grains is an indication for growth in confined space against compressive stress. At $\mathrm{Opx} / \mathrm{Ol}$ in rims around olivine grains such textures are less pronounced, but still locally present. Both growth fabrics indicate, that there was no transient porosity at the $\mathrm{Opx} / \mathrm{Ol}$ interface during rim growth in either of the two arrangements.

\section{Rim thickness}

Having identified rheology as the source for different crystallisation conditions at the opposite interfaces in the two core-rim-arrangements, the differerent rim growth rates await explanation depending on the mechanical behavior of the respective minerals. The studied orthopyroxene-forming reaction has a negative reaction volume $\left(\Delta_{\mathrm{r}} \mathrm{V}=-6 \%\right)$ and is forced by increased pressure. In both core-rim geometries rim growth has to be accompanied by compaction of the matrix surrounding the reaction sites. As an ad hoc approximation one of the matrix materials may be assumed to be rigid, in the sense that the strain rate of the matrix under constant external load cannot keep up with the volume loss of the growing orthopyroxene rim, and the other to be soft, such that creep of the matrix always perfectly compensates the volume loss associated with orthopyroxene growth at zero flow stress. Under such conditions, in the latter case the full ambient pressure would contribute to the energy budget of the reaction, whereas in the former situation the rim would release itself from external pressure. Since the driving force for rim growth equals $\Delta \mathrm{G}_{\mathrm{r}}$ both for the immobile$\mathrm{SiO}_{2}$ and immobile-MgO scenarios (Yund, 1997), orthopyroxene growth in either case is directly linked to the pressure at the growth sites. Taken to the extreme, the cores of the structures could be under $1 \mathrm{GPa}$ confining pressure in the soft matrix scenario, and virtually zero pressure in the rigid matrix scenario. In this situation, $\Delta_{\mathrm{r}} \mathrm{G}$ would decrease from 9.6 $\mathrm{kJmol}^{-1}$ (perfectly soft matrix) to $3.6 \mathrm{kJmol}^{-1}$ (perfectly rigid matrix) (data from Robie \& Hemingway, 1995). As rim thickness squared $\left(\mathrm{d}^{2}\right)$ at isothermal-isobaric conditions is proportional to $\Delta_{\mathrm{r}} \mathrm{G}, \mathrm{d}^{2}$ after given time in the two scenarios should differ by a value of about 3. This comes close to the differences actually observed in the rims of QFFQ01 and QFFQ02 (Table 1). In this interpretation quartz is the rigid and olivine the soft matrix.

However, despite the good fit of the numbers, this ad hoc model requires extremely high stresses to be held from very thin reaction rims which from a mechanical standpoint seems hardly realistic. To refine the model, one may assume that the compaction of the matrix can always keep up with reaction-induced volume loss, but that the deformation of the matrix uses up most of the externally provided mechanical energy, such that $\mathrm{d}^{2}$ would depend on $\Delta_{\mathrm{r}} \mathrm{G}$ in a similar way as discussed above without requiring extreme stress to be held from thin reaction rims. Under this assumption the "perfectly rigid" and "perfectly soft" scenarios represent the 
extreme cases for the effect of matrix rheology on rim growth rates. At the strain rates necessary to account for the negative reaction volume in our experiments, the effective viscosity of quartz (Luan \& Paterson, 1990) and olivine (Hirth \& Kohlstedt, 2003) are very close, whereby wet olivine might be softer than relatively dry quartz (Schmid et al., this volume). Our experiments give no direct hint to the deformation process actually at play. Due to the small grain size in the matrix in both arrangements our experiments may belong to the grain-size sensitive flow regime with respect to one or both reactants (for an extended review of the rheology of olivine and quartz-rich rocks see Bürgmann and Dresen, 2008). Therefore it must be conceded that the chemical-mechanical interplay in both core/rim geometries depending on the viscosity of the matrix phases cannot be predicted ad hoc but is the subject of part II of this joint investigation (Schmid et al., this volume).

Our interpretation demands the existence of a strain gradient around each reaction site, but no flow microstructures can be reported in support of this model. This absence can be explained by the very small magnitude of radial deformation around each inclusion, that in all cases is less than $1 \mu \mathrm{m}$ towards the rim/matrix interface and thus far smaller than the mean grain size of the matrix minerals. The mean strain rates in the single-capsule experiments are in the range of 0.004 to $0.009 \mu \mathrm{m} / \mathrm{h}$, and due to the exponential rate law for diffusion-controlled rim growth much smaller in the later stages of the experiments. Therefore the matrix microstructure should rather have the appearance to be expected after a static recrystallization experiment, as it does.

The central insight from this analysis of rim growth rates is the conclusion that the driving force for rim growth is not just the gradient in chemical potential of the diffusing components as buffered by local equilibria at the rim interfaces (e.g. Fisher, 1978), but the sum of chemical and mechanical contributions to the effective chemical potential gradients. For phase transformation reactions under volume change the effect of strain energy on reaction kinetics has been shown experimentally, for example for the olivine-spinel (Liu et al., 1998; Mosenfelder et al., 2000), coesite-quartz (Mosenfelder \& Bohlen, 1998) and aragonite-calcite (Liu \& Yund, 1993) transformations. Generally, transformation stress acts to inhibit reaction kinetics and may quench phase transformation reactions. Our experiments demonstrate that the effect of reaction-induced stress is similarly important in the context of net transfer reactions in the solid state that imply volume change, with all consequences known from phase transformations. Forsterite-rich olivine and quartz have no common stability field in $P$ $T$ space, so that reaction-induced stress affects reaction kinetics, but does not suppress the reaction to orthopyroxene. In other mineral reactions, however, reaction-induced stress may lead to local equilibria between mineral pairs that are out of equilibrium at ambient conditions and thus the quenching or suppression of mineral reactions.

The scenarios viable to explain the orthopyroxene growth structures and the positions of the initial Ol/Qtz interface relative to rim width in the two arrangements are similar to the case of slightly more mobile $\mathrm{MgO}\left(J_{\mathrm{MgO}} / J_{\mathrm{SiO}_{2}} \leq 1.5\right.$; Fig. $\left.6 \mathrm{~b}\right)$ where minor shifts in relative fluxes would not be identified at the resolution of our investigation. It thus appears that volume preservation at the compressive orthopyroxene growth site $(\mathrm{Ol} / \mathrm{Opx}$ interface) is followed as a general principle of total energy minimisation. Following this argument, the upper limit of $\mathrm{SiO}_{2}$-flux is set by the volume relations at the Ol/Opx interface in the present situation. The relative mobility of the $\mathrm{MgO}$ and $\mathrm{SiO}_{2}$ components at given $\mathrm{P}, \mathrm{T}, \mathrm{fH} \mathrm{H}_{2} \mathrm{O}$ thus is expected to vary between different mineral reactions and to be determined by the volume available for reactant growth under the directive of minimising stress at compressive sites.

Our experiments therefore indicate that the absolute and relative diffusive mobility of chemical components during rim growth is not just a function of $P, T, f H_{2} O$, but at given $P, T$, $\mathrm{fH}_{2} \mathrm{O}$ it is a function of local volume changes and the rheological properties of the 
surrounding phases. In a large number of field studies, relative diffusivities of chemical components (often normalized to $\mathrm{SiO}_{2}$ mobility) were deduced from corona structures, driven by the motivation to deduce the specific mobility of chemical components during metamorphism (see introduction). Our experiments show that any investigation on diffusive mobility of components in reaction rims and coronas is incomplete without a consideration of reaction-induced stress in response to local volume changes.

\section{ACKNOWLEDGEMENTS}

We thank the three reviewers for their thorough comments that substantially helped to improve this paper. We appriciate the cooperative spirit at MPI, University of Basel where the sample preparation and large parts of the evaluation have been done. This research was generously funded by the German Science Foundation (DFG) (grant MI1205/2). 


\section{REFERENCES}

Abart, R., Schmid, R. \& Harlov D. E., 2001. Metasomatic coronas around hornblendite xenoliths in granulite facies marble, Ivrea zone, N. Italy I: constraints on component mobility. Contributions to Mineralogy and Petrology, 141, 473-493.

Abart, R., Kunze, K., Milke, R., Sperb, R. \& Heinrich, W., 2004. Silicon and oxygen selfdiffusion in enstatite polycrystals: the Milke et al. (2001) rim growth experiments revisited. Contributions to Mineralogy and Petrology, 147, 633-646.

Ashworth, J. R. \& Birdi, J. J., 1990. Diffusion modelling of coronas around olivine in an open system. Geochimica et Cosmochimica Acta, 54, 2389-2401.

Ashworth, J. R., Birdi, J. J. \& Emmett, T. F., 1992a. A complex corona between olivine and plagioclase from the Jotun Nappe, Norway, and the diffusion modelling of multimineralic layers. Mineralogical Magazine, 56, 511-525.

Ashworth, J. R., Birdi, J. J. \& Emmett, T.F., 1992b. Diffusion in coronas around clinopyroxene: modelling with local equilibrium and steady state, and a non-steady-state modification to account for zoned actinolite-hornblende. Contributions to Mineralogy and Petrology, 109, 307325 .

Ashworth, J. R. \& Sheplev, V.S., 1997. Diffusion modelling of metamorphic layered coronas with stability criterion and consideration of affinity. Geochimica et Cosmochimica Acta, 61, 3671-3689.

Ashworth, J. R., Sheplev, V. S., Bryxina, N. A., Kobolov, V. Y. \& Reverdatto V.V.,1998. Diffusion-controlled corona reaction and overstepping of equilibrium in a garnet granulite, Yenisei Ridge, Siberia. Journal of Metamorphic Geology, 16, 231-246.

Attoh, K., 1998. Models for orthopyroxene-plagioclase and other corona reactions in metanorites, Dahomeyide orogen, West Africa. Journal of Metamorphic Geology, 16, 345362.

Bai, Q. \& Kohlstedt, D. L., 1993. Effects of chemical environment on the solubility and incorporation mechanism for hydrogen in olivine. Physics and Chemistry of Minerals, 19, 460-471.

Bell, D. R., Rossman, G. R., Maldener, J., Endisch, D. \& Rauch, F., 2003. Hydroxide in olivine: A quantitative determination of the absolute amount and calibration of the IR spectrum. Journal of Geophysical Research, Solid Earth, 108 (B2), Art. No. 2105

Bürgmann, R. \& Dresen, G., 2008. Rheology of the lower crust and upper mantle: Evidence from rock mechanics, geodesy, and field observations. Annual Review of Earth and Planetary Science, 36, 531-567.

Carlson, W. D., 2002. Scales of disequilibrium and rates of equilibration during metamorphism. American Mineralogist, 87, 185-204.

Carlson, W. D. \& Johnson, C. D., 1991. Coronal reaction textures in garnet amphibolites of the Llano Uplift. American Mineralogist, 76, 756-772.

Carlson, W. D., Denison, C. \& Ketcham, R. A., 1995. Controls on the nucleation and growth of porphyroblasts: kinetics from natural textures and numerical models. Geological Journal, 30, 207-225.

Carmichael, D. M., 1987. Induced stress and secondary mass transfer: thermodynamic basis for the tendency toward constant-volume constraint in diffusion metasomatism. In: Chemical transport in metasomatic processes, NATO ASI Series C 218 (ed. Helgeson, H. C.), pp. 239264. Reidel, Dordrecht. 
Chopin, C., Henry, C. \& Michard, A., 1991. Geology and petrology of the coesite-bearing terrain, Dora Maira massif, Western Alps. European Journal of Mineralogy, 3, 263-291.

Fisher, G. W., 1978. Rate laws in metamorphism. Geochimica et Cosmochimica Acta, 42, 1035-1050.

Fisler, D. K. \& Mackwell S. J., 1994. Kinetics of diffusion-controlled growth of fayalite. Physics and Chemistry of Minerals, 21, 156-165.

Fisler, D. K., Mackwell, S. J. \& Petsch, S., 1997. Grain boundary diffusion in enstatite. Physics and Chemistry of Minerals, 24, 264-273.

Foster, C. T. Jr., 1981. A thermodynamic model of mineral segregations in the lower sillimanite zone near Rangeley, Maine. American Mineralogist, 66, 260-277.

Foster, C. T., 1999. Forward modeling of metamorphic textures. Canadian Mineralogist, 37, 415-429.

Grant, S. M., 1988. Diffusion models for corona formation in metagabbros from the Western Grenville Province, Canada. Contributions to Mineralogy and Petrology, 98, 49-63.

Griffin, W. L., 1971. Genesis of coronas in anorthosites of the Upper Jotun Nappe, Indre Sogn, Norway. Journal of Petrology, 12, 219-243.

Griffin, W. L., Mellini, M., Oberti, R. \& Rossi, G., 1985. Evolution of coronas in Norwegian anorthosites : reevaluation based on crystal-chemistry and microstructures. Contributions to Mineralogy and Petrology, 91, 330-339.

Guiraud, M. \& Powell, R., 2006. P-V-T relationships and mineral equilibria in inclusions in minerals. Earth and Planetary Science Letters, 244, 683-694.

Hirth, G. \& Kohlstedt, D. L., 1995. Experimental constraints on the dynamics of the partially molten Upper Mantle - deformation in the diffusion creep regime. Journal of Geophysical Research, 100 (B 2), 1981-2001.

Hirth, G. \& Kohlstedt, D. L., 2003. Rheology of the Upper Mantle and the Mantle Wedge: A View From the Experimentalists. In: Inside the Subduction Factory. Geophysical Monograph. (ed. Eiler, J.), American Geophysical Union, Washington, pp. 83-105.

Joesten, R., 1986. The role of magmatic reaction, diffusion and annealing in the evolution of coronitic microstructure in troctolitic gabbro from Risör, Norway. Mineralogical Magazine, 50, 441-467.

Joesten, R. \& Fisher G. W., 1988. Kinetics of diffusion-controlled mineral growth in the Christmas Mountains (Texas) contact aureole. Geological Society of America Bulletin, 100, 714-732.

Joesten, R., 1991a. Grain-boundary diffusion kinetics in silicate and oxide minerals. In: Diffusion, atomic ordering, and mass transport (ed Ganguly, J.). Springer, New York, pp. 345-395.

Johnson, C. D. \& Carlson, W.D., 1990. The origin of olivine-plagioclase coronas in metagabbros from the Adirondack Mountains, New York. Journal of Metamorphic Geology, 8, 697-717.

Libowitzky, E. \& Rossman, G. R., 1997. An IR absorption calibration for water in minerals. American Mineralogist, 82, 1111-1115.

Liu, M. \& Yund, R. A., 1993. Transformation kinetics of polycrystalline aragonite to calcite: new experimental data, modelling, and implications. Contributions to Mineralogy and Petrology, 114, 465-478. 
Liu, M. \& Yund, R. A., 1995. The elastic strain energy associated with the olivine-spinel transformation and its implications. Phys Earth Planet Inter 89, 177-197.

Liu, M., Peterson, J. \& Yund R. A., 1997. Diffusion-controlled growth of albite and pyroxene reaction rims. Contributions to Mineralogy and Petrology, 126, 217-223.

Liu, M., Kerschhofer, L., Mosenfelder, J. L.\& Rubie, D. C., 1998. The effect of strain energy on growth rates during the olivine-spinel transformation and implications for olivine metastability in subducting slabs. Journal of Geophysical Research, Solid Earth, 103 (B10), 23897-23909.

Luan, F. C. \& Paterson, M. S. 1992. Preparation and deformation of synthetic aggregates of quartz. Journal of Geophysical Research, Solid Earth, 97 (B1), 301-320.

Markl, G., Foster, C. T. \& Bucher K., 1998. Diffusion-controlled olivine corona textures in granitic rocks from Lofoten, Norway: Calculation of Onsager diffusion coefficients, thermodynamic modelling and petrologic implications. Journal of Metamorphic Geology, 16, 607-623.

Matveev, S., O'Neill, H. S. C., Ballhaus, C., Taylor, W. R. \& Green, D. H., 2001. Effect of silica activity on $\mathrm{OH}-\mathrm{IR}$ spectra of olivine: implications for $\mathrm{Low}-a \mathrm{SiO}_{2}$ mantle metasomatism. Journal of Petrology, 42, 721-729.

Merino, E. \& Dewers, T., 1998. Implications of replacement for reaction-transport modeling. Journal of Hydrology, 209, 137-146.

Milke, R., Wiedenbeck, M. \& Heinrich, W., 2001. Grain boundary diffusion of Si, Mg, and O in enstatite reaction rims: a SIMS study with isotopically doped reactands. Contributions to Mineralogy and Petrology, 142, 15-26.

Milke, R. \& Heinrich, W., 2002. Diffusion-controlled growth of wollastonite rims between quartz and calcite: Comparison between nature and experiment. Journal of Metamorphic Geology, 20, 467-480.

Milke, R. \& Wirth R., 2003. The formation of columnar fiber texture in wollastonite rims by induced stress and implications for diffusion-controlled corona growth. Physics and Chemistry of Minerals, 30, 230-242.

Milke, R., Dohmen, R., Becker, H. W. \& Wirth, R., 2007. Growth kinetics of enstatite reaction rims studied on nano-scale, Part I: Methodology, microscopic observations and the role of water. Contributions to Mineralogy and Petrology, 154, 519-533.

Miller, G. H., Rossman, G. R. \& Harlow, G. E., 1987. The natural occurence of hydroxide in olivine. Physics and Chemistry of Minerals, 14, 461-472.

Mongkoltip, P. \& Ashworth, J. R., 1983. Quantitative estimation of an open-system symplectite-forming reaction: restricted diffusion of $\mathrm{Al}$ and $\mathrm{Si}$ in coronas around olivine. Journal of Petrology, 24, 635-661.

Mosenfelder, J. L. \& Bohlen, S. R., 1997. Kinetics of the coesite to quartz transformation. Earth and Planetary Science Letters, 153, 133-147.

Mosenfelder, J. L., Connolly, J. A. D., Rubie, D. C. \& Liu, M., 2000. Strength of $(\mathrm{Mg}, \mathrm{Fe})_{2} \mathrm{SiO}_{4}$ wadsleyite determined by relaxation of transformation stress. Physics of the Earth and Planetary Interiors, 120, 63-78.

Nishiyama T., 1983. Steady diffusion model for olivine-plagioclase corona growth. Geochimica et Cosmochimica Acta, 47, 283-294. 
Paterson, M. S., 1982. The determination of hydroxyl by infrared-adsorption in quartz, silicate- glasses and similar materials. Bulletin de Mineralogie, 105, 20-29.

Putnis, A., 2002. Mineral replacement reactions: from macroscopic observations to microscopic mechanisms. Mineralogical Magazine, 66, 689-708.

Putnis, C. V. \& Mezger, K., 2004. A mechanism of mineral replacement: Isotope tracing in the model system KCl-KBr- $\mathrm{H}_{2} \mathrm{O}$. Geochimica et Cosmochimica Acta, 68, 2839-2848.

Robie, R. A. \& Hemingway, B. S., 1995. Thermodynamic properties of minerals and related substances at $298.15 \mathrm{~K}$ and 1 bar (105 Pascals) pressure and at higher temperatures. United States Geological Survey Bulletin, 2131, Washington.

Ruzicka, A., 1998. Growth of mineral zones by diffusion-controlled reactions: Theory and application to mesosiderites. American Journal of Science, 298, 1-29.

Sack, R. O., 1982. Reaction skarns between quartz-bearing and olivine-bearing rocks. American Journal of Science, 282, 970-1011.

Schmid, D. W., Podladchikov, Y. Y., Abart, R. \& Milke R., 2007. Matrix rheology effects on reaction rim growth II: Coupled diffusion and deformation models. Journal of Metamorphic Petrology, this volume.

Watson, E. B. \& Price, J. D., 2001. Kinetics of the reaction $\mathrm{MgO}+\mathrm{Al}_{2} \mathrm{O}_{3}=\mathrm{MgAl}_{2} \mathrm{O}_{4}$ and Al$\mathrm{Mg}$ interdiffusion in spinel at 1200-2000 ${ }^{\circ} \mathrm{C}$ and 1.0-4.0 GPa. Geochimica et Cosmochimica Acta, 66, 2123-2138.

Yund, R. A., 1997. Rates of grain boundary diffusion through enstatite and forsterite reaction rims. Contributions to Mineralogy and Petrology, 126, 224-236. 


\section{Figures:}

Fig. 1: Selected images of rims around olivine and quartz from QF01 and FQ01.

Fig. 2: Rim thicknesses measured along the capsule QFFQ02.

Fig. 3: FTIR spectra of olivine and quartz before and after reaction. a) Water peak in the 3450 $\mathrm{cm}^{-1}$ region on pressed olivine and quartz pellets during stepwise heating to $400{ }^{\circ} \mathrm{C}$; b) San Carlos olivine starting material; c) Spectra in quartz and olivine after experiment QFFQ01.

Fig. 4: Central part of QFFQ02 with olivine grains in quartz (left side), quartz grains in olivine (right) side, and an olivine grain in contact with the olivine matrix.

a) BSE image: Uneven orthopyroxene rim thickness around single clasts is due to cutting effects and is largely canceled out by the measuring routine.

b) EBSD image: Orthopyroxene rims around quartz have palisade texture, whereas the microstructures in rims around olivine are less obvious. Grain diameters in the quartz matrix $<20 \mu \mathrm{m}$, and in the olivine matrix $<30 \mu \mathrm{m}$ with some larger grains (upper right).

Fig. 5: Synopsis of microtextures in orthopyroxene rims around quartz and olivine, respectively. Combined from observations by optical microscopy, and foreward and backscattered electron microscopy. $\mathrm{LPO}=$ lattice-preferred orientation; $\mathrm{SPO}=$ shape-preferred orientation; $\mathrm{BSE}=$ electron back-scatter capacity.

Fig. 6: Schematic view of local volume changes for different ratios between the diffusive fluxes $J_{\mathrm{MgO}}$ and $J_{\mathrm{SiO}_{2}}$. The initial Ol/Qtz interface is taken to be fixed relative to an external reference frame. Stress is induced by local positive or negative reaction volume. Black areas: volume occupied by reactant and product (source of compressive stress); white areas: open volume (source of dilative stress).

a) Model situation for immobile $\mathrm{SiO}_{2}$. The original Ol/Qtz interface is located in the middle of the orthopyroxene rim. Orthopyroxene at $\mathrm{Ol} / \mathrm{Opx}$ crystallises in a dilative regime and at Qtz/Opx in a compressive regime. b) Model situation for volume conserving orthopyroxene growth at O1/Opx. The microfabrics of orthopyroxene rims around olivine are similar to this situation, which in spherical geometry comes close to situation c).

c) Model situation for dominantly $\mathrm{SiO}_{2}$ diffusion. The microfabrics of orthopyroxene rims around quartz are similar to this model situation. 
Tables

Table 1: Run conditions and rim thicknesses

\begin{tabular}{|l|l|l|l|l|l|l|}
\hline Experiment & $\mathbf{P}[\mathbf{G P a}]$ & $\mathbf{T}\left[{ }^{\circ} \mathbf{C}\right]$ & $\mathbf{t}[\mathbf{h}]$ & $\begin{array}{l}\mathbf{d}_{\text {Opx,Ol }} \\
{[\boldsymbol{\mu m}]}\end{array}$ & $\begin{array}{l}\mathbf{d}_{\text {Opx,Qtz }} \\
{[\boldsymbol{\mu m}]}\end{array}$ & $\mathbf{d}_{\text {Opx,Qtz }}{ }^{2} / \mathbf{d}_{\text {Opx,Ol }}{ }^{2}$ \\
\hline QF01 & 1 & 1000 & 80 & - & 29.8 & - \\
\hline FQ01 & 1 & 1000 & 80 & 3.2 & - & - \\
\hline QFFQ01 & 1 & 1000 & 80 & 6.1 & 10.3 & 2.85 \\
\hline QFFQ02 & 1 & 1000 & 80 & 10.2 & 14.1 & 1.91 \\
\hline
\end{tabular}

Table 2: FTIR measurements of intracrystalline and adsorbed water in starting samples and run products

\begin{tabular}{|l|l|l|}
\hline material & wt-ppm $\mathbf{H}_{\mathbf{2}} \mathbf{O}$ & $\mathbf{H} / \mathbf{1 0}^{\mathbf{6}} \mathbf{S i}$ \\
\hline Olivine starting material & $1.4 \pm 0.2$ & $22 \pm 3$ \\
\hline Ol-matrix after experiment & 76 & 1200 \\
\hline Ol-clasts after experiment & 79 & 1250 \\
\hline Qtz-clasts after experiment & 28 & 187 \\
\hline Ol pressed powder & up to 2400 & up to 37300 \\
\hline Qtz pressed powder & up to 2100 & up to 13980 \\
\hline
\end{tabular}


Fig. 1
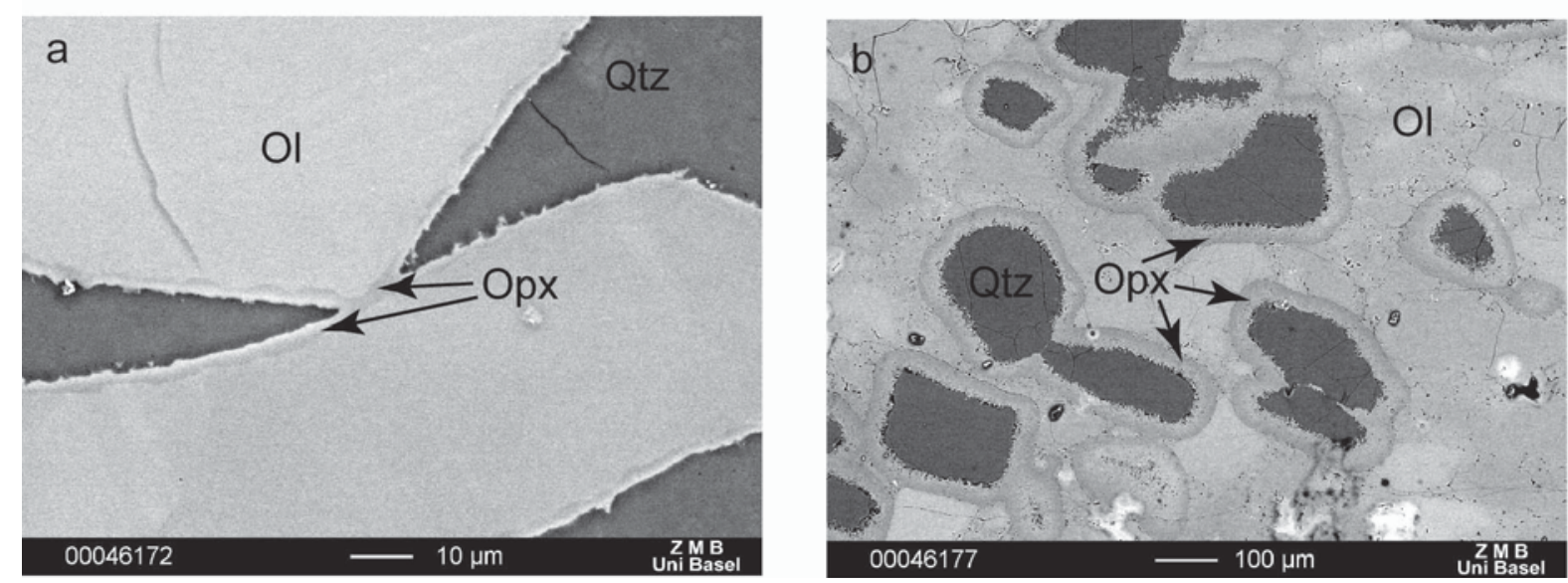

Fig. 2

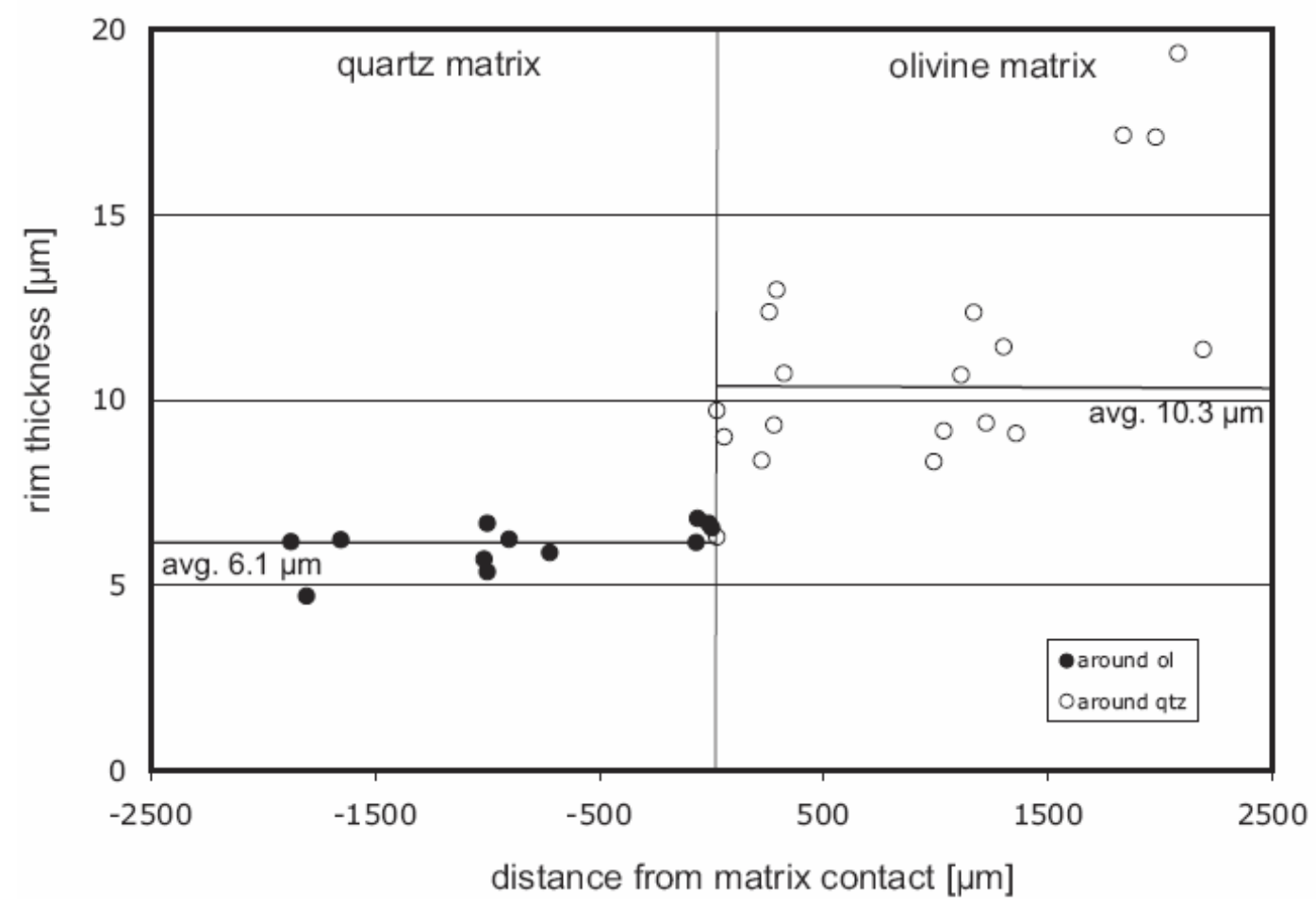


Fig. 3
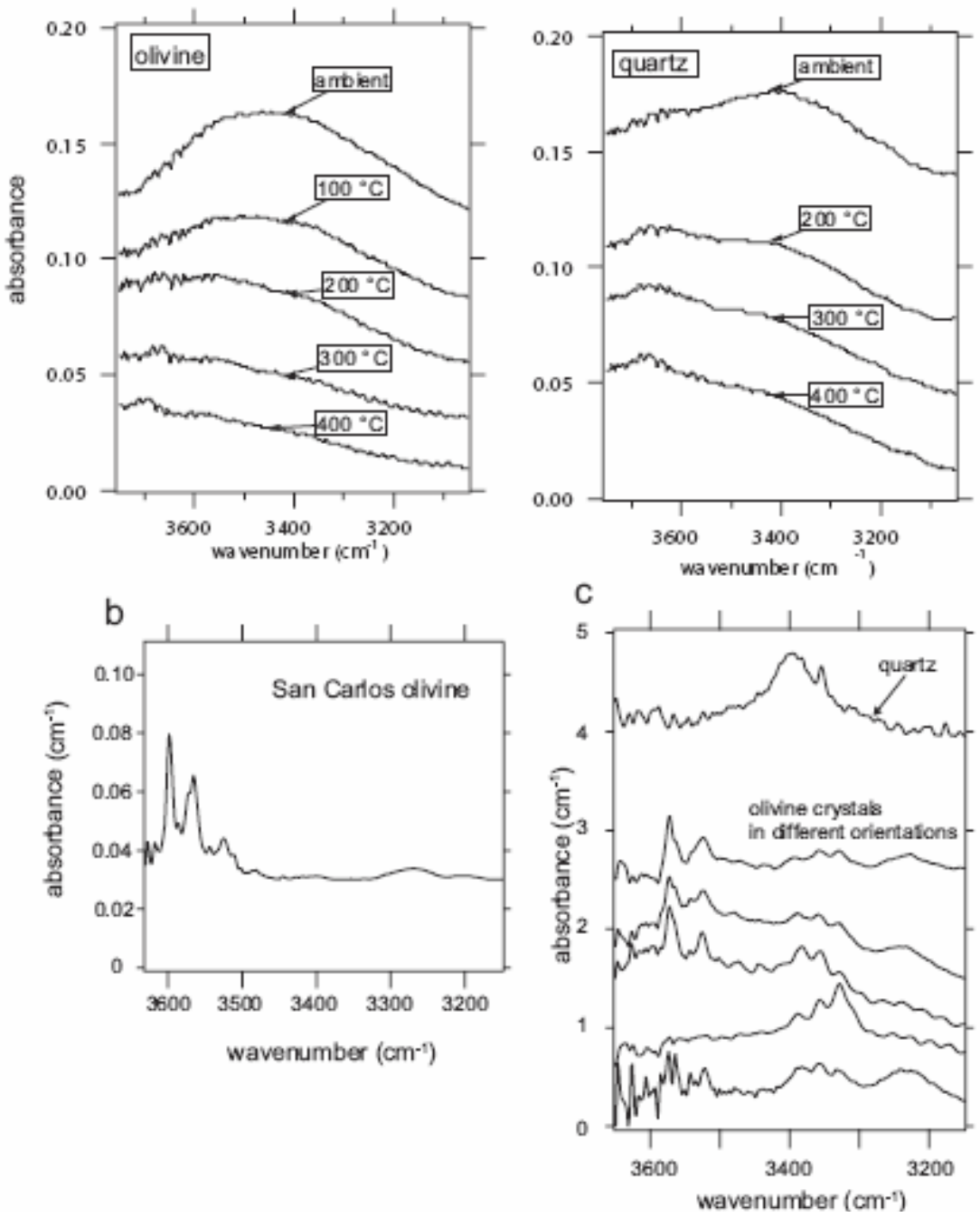
Fig. 4

a

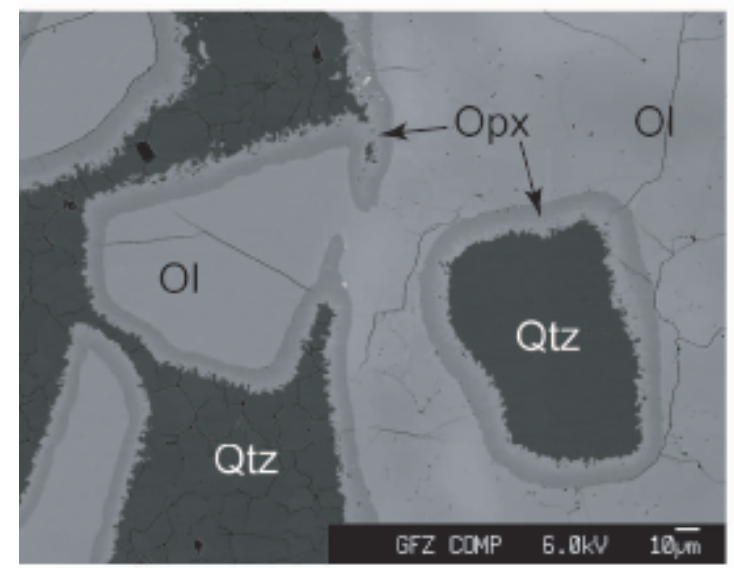

C

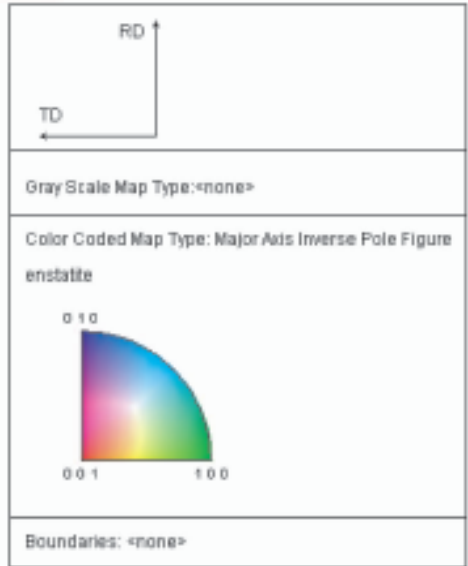

b
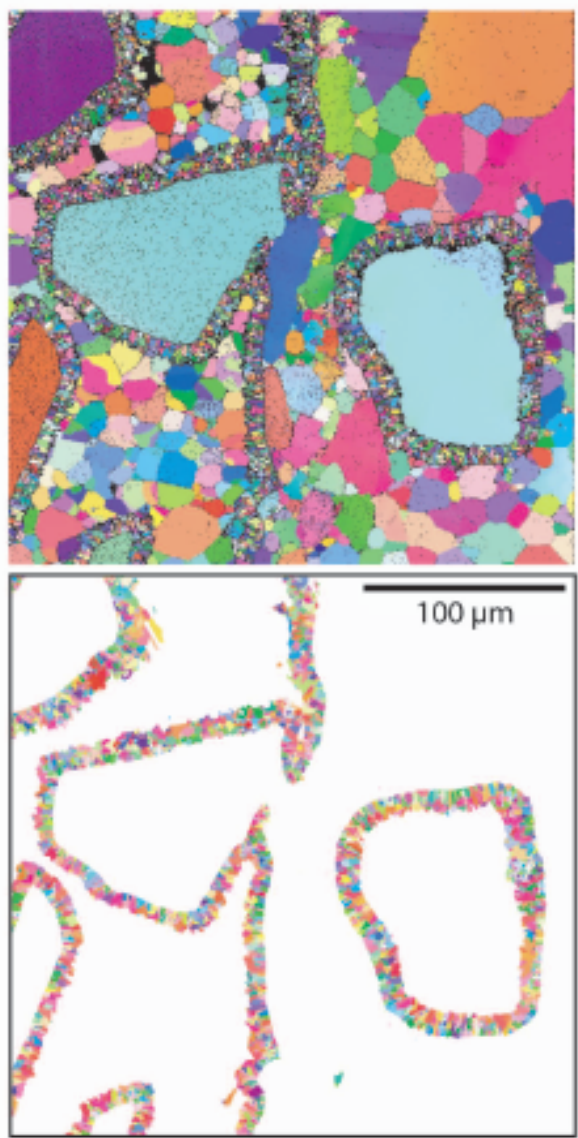
Fig. 5

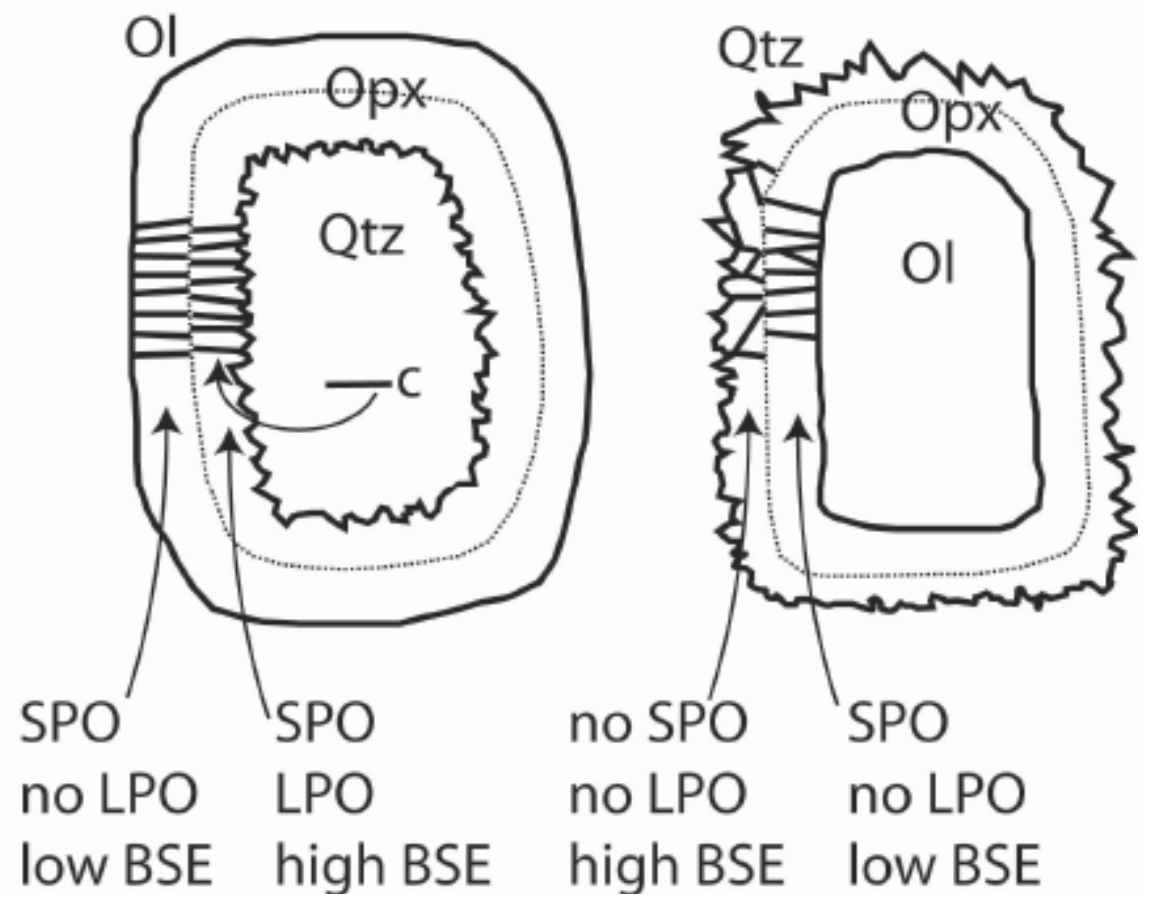


Fig. 6

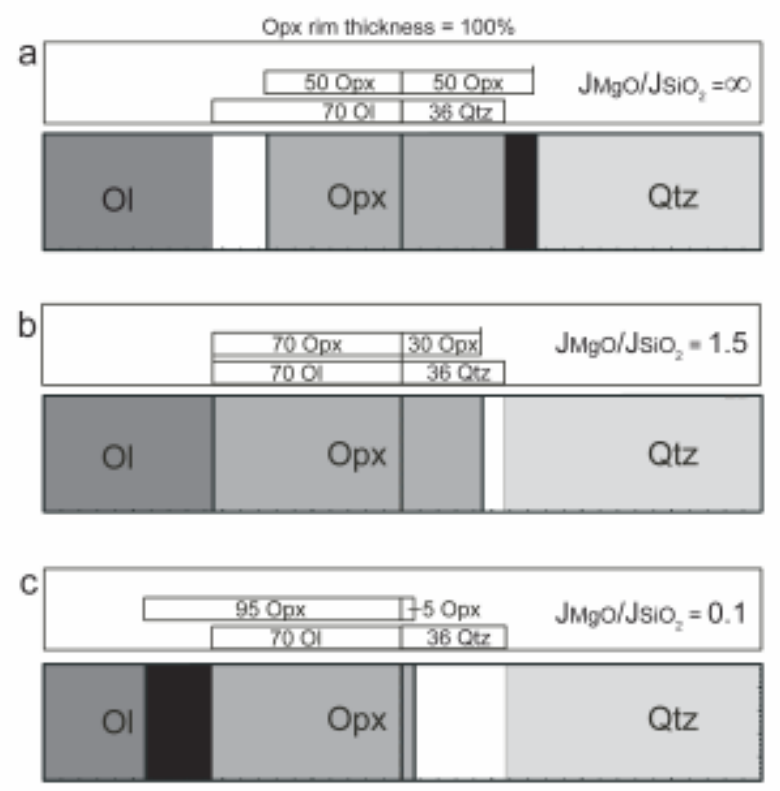

